\title{
O USO DA CIRURGIA GUIADA NA REABILITAÇÃO UNITÁRIA EM REGIÃO ESTÉTICA
}

Débora de Brito MORO, Geninho THOMÉ, Sérgio Rocha BERNARDES, Elisa Mattias SARTORI, Caio HERMANN

A Implantodontia tem sofrido grandes avanços desde a introdução do conceito da osseointegração, havendo uma busca contínua por um planejamento ideal, visando estética e função. Nesse sentido foram desenvolvidos protocolos de cirurgias guiadas por barras, a técnica da prototipagem e mais recentemente as cirurgias guiadas com planejamento virtual e sem abertura de retalho. O objetivo deste trabalho é descrever um caso clínico no qual foi realizada reabilitação unitária em região estética anterior por meio de implantes dentários a partir da técnica da cirurgia guiada. Paciente sexo masculino, 21 anos, compareceu à clínica do ILAPEO relatando perda do elemento 21 quando ainda na infância seguido de tratamento ortodôntico até a fase adulta para manutenção do espaço protético. Após exame, foi proposto tratamento com implantes osseointegrados com carga imediata e prótese provisória. Os implantes foram instalados por meio da técnica sem incisão e a provisória instalada imediatamente após a cirurgia. O caso recebeu acompanhamento clínico radiográfico durante 3 meses. A técnica da cirurgia guiada por meio do planejamento virtual promove ao paciente maior conforto durante o ato cirúrgico e pós-operatório, devido à técnica cirúrgica conservadora aliada ao resultado estético favorável. 